\title{
Acinetobacter tandoii ZM06 Assists Glutamicibacter nicotianae ZM05 in Resisting Cadmium Pressure to Preserve Dipropyl Phthalate Biodegradation
}

\author{
Xuejun Wang, Si Shen, Hao Wu, Haixia Wang, Lvjing Wang $\mathbb{D}$ and Zhenmei Lu* \\ MOE Laboratory of Biosystem Homeostasis and Protection, College of Life Sciences, Zhejiang University, \\ Hangzhou 310058, China; wxj941031@163.com (X.W.); sshen10@its.jnj.com (S.S.); wuhaochs@hotmail.com (H.W.); \\ lanedysia@hotmail.com (H.W.); wanglvjing@zju.edu.cn (L.W.) \\ * Correspondence: lzhenmei@zju.edu.cn
}

check for updates

Citation: Wang, X.; Shen, S.; Wu, H.; Wang, H.; Wang, L.; Lu, Z. Acinetobacter tandoii ZM06 Assists Glutamicibacter nicotianae ZM05 in Resisting Cadmium Pressure to Preserve Dipropyl Phthalate Biodegradation. Microorganisms 2021, 9, 1417. https://doi.org/10.3390/ microorganisms 9071417

Academic Editor: Nikolay Bojkov Vassilev

Received: 22 May 2021

Accepted: 28 June 2021

Published: 30 June 2021

Publisher's Note: MDPI stays neutral with regard to jurisdictional claims in published maps and institutional affiliations.

Copyright: (c) 2021 by the authors. Licensee MDPI, Basel, Switzerland. This article is an open access article distributed under the terms and conditions of the Creative Commons Attribution (CC BY) license (https:/ / creativecommons.org/licenses/by/ $4.0 /)$.
Abstract: Dipropyl phthalate (DPrP) coexists with cadmium as cocontaminants in environmental media. A coculture system including the DPrP-degrading bacterium Glutamicibacter nicotianae ZM05 and the nondegrading bacterium Acinetobacter tandoii ZM06 was artificially established to degrade DPrP under Cd(II) stress. Strain ZM06 relieved the pressure of cadmium on strain ZM05 and accelerated DPrP degradation in the following three ways: first, strain ZM06 adsorbed Cd(II) on the cell surface (as observed by scanning electron microscopy) to decrease the concentration of $\mathrm{Cd}$ (II) in the coculture system; second, the downstream metabolites of ZM05 were utilized by strain ZM06 to reduce metabolite inhibition; and third, strain ZM06 supplied amino acids and fatty acids to strain ZM05 to relieve stress during DPrP degradation, which was demonstrated by comparative transcriptomic analysis. This study provides an elementary understanding of how microbial consortia improve the degradation efficiency of organic pollutants under heavy metals contamination.

Keywords: metatranscriptomics; Glutamicibacter nicotianae ZM05; Acinetobacter tandoii ZM06; cooperation; DPrP biodegradation; cadmium pressure

\section{Introduction}

Phthalic Acid Esters (PAEs), as plasticizers, can migrate out from plastic materials into the environment during their production and disposal [1]. Dipropyl phthalate (DPrP), as a kind of PAEs with mutagenic, teratogenic, and carcinogenic properties, has been classified as a priority pollutant by the United States Environmental Protection Agency [2] Furthermore, it has recently been proven that DPrP causes cacoethic effects on human health by interfering with endogenous hormones [3].

In environments such as soil and groundwater, PAEs often cocontaminate with heavy metals. Compared with that of individual contamination, the remediation of cocontamination with organic pollutants and heavy metals is a more complicated problem owing to the combined toxicity and potential interactions of contaminants $[4,5]$. Cadmium $(\mathrm{Cd})$ and PAEs are of particular concern due to their migration and bioaccumulation [6], potentially harmful effects on the ecosystem and human health, and frequent occurrence in several types of anthropogenic contaminated sites. Agricultural production with cadmium content in fertilizer applications and atmospheric cadmium dust settlement directly causes the copollution of cadmium and PAEs $[7,8]$. A large body of evidence actually shows that PAEs and heavy metals coexist in the environment [9-11].

Microorganisms play crucial roles in biogeochemical cycling in ecosystems [12] and may mediate metal detoxification [13] and the biodegradation of organic compounds [14]. However, previous studies have shown that heavy metals have an adverse impact on the microbial degradation of organic pollutants by repressing microbial activity [12]. Hence, for the remediation of cocontamination with organic compounds and heavy metals, microbial 
consortia exhibit superior biodegradation performance [15,16]. Compared with a single strain, bacterial consortia can facilitate the degradation of organic pollutants by improving environmental adaptability [17], alleviating environmental stress [15], and cooperating with metabolite-degrading bacteria [18]. For example, the cadmium-resistant bacterium Pseudomonas sp. H1 enhanced the degradation of 2,4-dichlorophenoxyacetic acid by Ralstonia eutropha JMP134 in the presence of $60 \mu \mathrm{g} / \mathrm{g}$ cadmium by reducing the stress [19]. Interactions between microorganisms play important roles in the degradation of hazardous materials. Therefore, constructing bacterial consortia that resist heavy metals and degrade organic pollutants is an ideal solution for remediating combined contamination, and it is essential to explore the interaction mechanisms of microbial cooperative degradation during remediating cocontamination.

Based on a previous study of ours, an efficient PAEs-degrading bacterium was identified as Glutamicibacter nicotianae ZM05, which could degrade most short-chain PAEs, including dibutyl phthalate (DBP), DPrP, diethyl phthalate (DEP), and dimethyl phthalate (DMP) [20]. Nevertheless, the growth and degradation ability of strain ZM05 were depressed under heavy metal contamination, especially cadmium pollution. In this study, an artificially constructed consortium composed of the DPrP-degrading bacterium ZM05 and the nondegrading bacterium Acinetobacter tandoii ZM06 effectively resisted the inhibition of DPrP degradation by $\mathrm{Cd}$ (II) stress. To study the cooperative interactions during degradation strains ZM05 and ZM06 were cocultured under Cd(II) stress or without Cd(II) stress and subjected to metatranscriptomics. We centered on the differences in DPrP degradation and gene expression in the degrading bacterium ZM05 between the monoculture and coculture systems with and without Cd(II) stress.

\section{Materials and Methods}

\subsection{Chemicals and Media}

Di-n-propyl phthalate (DPrP, $>98 \%$ purity), diethyl phthalate (DEP, $>99 \%$ purity), dimethyl phthalate (DMP, $>99 \%$ purity), monomethyl phthalate (MMP, $>97 \%$ purity), and phthalic acid (PA, $>99.5 \%$ purity) were purchased from Aladdin Industrial Corporation (Shanghai, China), while monoethyl phthalate (MEP, $>98 \%$ purity) was purchased from Solarbio Science \& Technology Co., Ltd. (Beijing, China), and protocatechuic acid (PCA, $>99 \%$ purity) was purchased from Macklin Biochemical Co., Ltd. (Shanghai, China).

Minimal salt medium (MSM) supplemented with DPrP was used to isolate and culture DPrP-degrading bacterium. MSM was prepared with the following components (per liter): $5.8 \mathrm{~g} \mathrm{~K}_{2} \mathrm{HPO}_{4}, 4.5 \mathrm{~g} \mathrm{KH}_{2} \mathrm{PO}_{4}, 2.0 \mathrm{~g}\left(\mathrm{NH}_{4}\right)_{2} \mathrm{SO}_{4}, 0.34 \mathrm{~g} \mathrm{MgCl}_{2} \cdot 6 \mathrm{H}_{2} \mathrm{O}$, and $1 \mathrm{~mL}$ trace element medium stock solution (per liter: $2.6 \mathrm{~g} \mathrm{CaCl}_{2} \cdot 2 \mathrm{H}_{2} \mathrm{O}, 0.18 \mathrm{~g} \mathrm{FeSO} \cdot 7 \mathrm{H}_{2} \mathrm{O}, 0.15 \mathrm{~g} \mathrm{MnCl}_{2} \cdot 4 \mathrm{H}_{2} \mathrm{O}$ and $0.24 \mathrm{~g} \mathrm{Na}_{2} \mathrm{MoO}_{4} \cdot 2 \mathrm{H}_{2} \mathrm{O}$ ). A Luria-Bertani broth was used to isolate and culture the nondegrading bacterium.

\subsection{Isolation and Identification of the DBP-Degrading Bacterium and Cooperative Bacterium}

After enrichment and selection with $1000 \mathrm{mg} / \mathrm{L}$ DPrP, the most efficient strain isolated from agricultural surface layer soils (Hangzhou, Zhejiang Province, China) was selected and designated as ZM05. Strain ZM05 colonies were white, and the morphology of strain $\mathrm{ZM} 0$ was $\mathrm{G}^{+}$, rod-shaped and motile. The basic criterion for assessing species boundaries is to estimate the genetic relatedness between two genomes [21]. The whole-genome orthologous average nucleotide identity (ANI) values were calculated using an online server: http:/ / enve-omics.ce.gatech.edu/ani/ (accessed on 22 June 2021) [22]. And organisms belonging to the same species typically showing $\geq 95 \%$ ANI among themselves [21]. The results of ANI between strain ZM05 (GenBank Accession No. CP059853.1) and Glutamicibacter nicotianae OTC-16 (GenBank Accession No. GCA_003687415.1) was 98.53\%. Thus, based on morphological characteristics and ANI calculation of genome, the isolated DBP-degrading bacterium was identified as Glutamicibacter nicotianae strain ZM05.

The cooperative bacterium ZM06 was isolated from the same soil samples by using LB plates. Strain ZM06 colonies were white, and the morphology of strain ZM06 was 
$\mathrm{G}^{-}$, rod-shaped and motile. The results of ANI between strain ZM06 (NCBI accession ID: PRJNA739801) and Acinetobacter tandoii SE63 (GenBank Accession No. GCA_006965565.1) was $96.25 \%$. Based on morphological characteristics and ANI calculation of genome, the isolated nondegrading bacterium was identified as Acinetobacter tandoii strain ZM06.

\subsection{Monoculture and Coculture Experiments}

Early stationary-phase cells of strain ZM05 $\left(\mathrm{OD}_{600}=1.80\right)$ or $\mathrm{ZM} 06\left(\mathrm{OD}_{600}=1.25\right)$ were centrifuged (4 min, 10,000 rpm) and suspended in MSM. Strains ZM05 and ZM06 were inoculated in seventy milliliters of MSM (with or without $0.8 \mathrm{mM} \mathrm{CdCl}_{2}$ ) with $1000 \mathrm{mg} / \mathrm{L}$ $\mathrm{DPrP}$ to the initial $\mathrm{OD}_{600}$ of 0.03 , respectively. The monoculture system was inoculated with the same amount of strain ZM05. Coculture and monoculture experiments were conducted in Erlenmeyer flasks with three replicates at $30^{\circ} \mathrm{C}$ and $200 \mathrm{rpm}$.

\subsection{Sample Preparation and Analysis}

Samples were collected to determine the concentrations of DPrP, its metabolites, and $\mathrm{Cd}$ (II) during incubation. Extraction and detection of DPrP were carried out according to the method described previously [23]. The metabolites produced during the degradation process were identified by HPLC-MS [24]. The amino acids and fatty acids in the supernatant were detected by LC-MS [25] and GC-MS [26], respectively. The adsorption of Cd(II) on the surface and inside of bacteria was determined by scanning electron microscopy (SEM), transmission electron microscopy (TEM), and energy dispersive spectroscopy (EDS) [27]. The $\mathrm{Cd}$ (II) concentration in the supernatant was investigated by ICP-MS (Agilent Technologies 7800 ICP-MS) analysis [28]. Quantitative PCR (qPCR) was used to quantify the ratio of DNA levels of the specific est $G / x c p R$ genes to determine the ratios of ZM05 to ZM03 in the coculture system under Cd(II) stress [29,30]. The primers used in qPCR are listed in Supplementary Table S1. For the transcriptional analysis, $\mathrm{CK}$ (control), CD (monoculture under $0.8 \mathrm{mM} \mathrm{Cd}^{2+}$ ), and $\mathrm{CO}$ (coculture under $0.8 \mathrm{mM} \mathrm{Cd}^{2+}$ ) samples were harvested for RNA extraction, and sample information is provided in Table S2.

\section{5. cDNA Library Construction and RNA-Seq}

Total RNA was extracted using the RNeasy Mini Kit (QIAGEN, Hilden, Germany) according to the instructions. RNA quality was monitored on $1 \%$ agarose gels, and RNA quantity was measured using Nanodrop One (Thermo Fisher Scientific, Waltham, MA, USA). rRNA was depleted by Ribo-Zero Magnetic Kit (Epicentre) according to the instructions. The RNA samples were subsequently sent to the Guangdong Magigene Biotechnology Co., Ltd. (Guangzhou, China) for library preparation and sequencing. Library preparation was conducted with a NEBNext ${ }^{\circledR}$ Ultra II ${ }^{\mathrm{TM}}$ Directional RNA Library Prep Kit (Illumina, San Diego, CA, USA) according to standard protocols. After cluster generation, the library was sequenced on an Illumina HiSeq Xten platform, and $150 \mathrm{bp}$ paired-end reads were generated [31].

\subsection{RNA-Seq Data Analysis}

Raw data in fastq format were processed by Trimmomatic (v.0.36) to acquire clean reads, and clean reads were mapped to NCBI Rfam databases to remove the rRNA sequences by Bowtie 2 (v2.33). The remaining mRNA sequences were mapped to the reference genome by Hisat2 (2.1.0) [32]. The HTSeq-count (v0.9.1) was used to obtain the read count and function information of each gene were obtained by HTSeq-count (v0.9.1) according to the mapping results [33]. To make the expression levels of genes comparable among different genes and different experiments, the RPKM was calculated. The read count of each gene was used for differential expression analysis [34]. Differentially expressed genes (DEGs) were identified using edgeR (v3.16.5) [35]. The resulting $p$-value was corrected by Benjamini and Hochberg's approach for controlling the false discovery rate (FDR). Genes with FDR $\leq 0.05$ and $\mid \log _{2}$ (fold change) $\mid \geq 1$ were considered candidate DEGs. In addition, those genes were used for KEGG (Kyoto Encyclopedia of Genes and Genomes) 
enrichment analyses by clusterProfiler (v3.4.4) [36], and gene length bias was corrected. KEGG pathways with FDR $\leq 0.05$ were considered significantly enriched. Raw data are deposited in the NCBI (accession ID: PRJNA699047, PRJNA699094, and PRJNA699127).

\section{Results}

\subsection{Construction of a Synergistic Community under Cd Pressure}

Strain ZM05 completely degraded $1000 \mathrm{mg} / \mathrm{L}$ DPrP in $24 \mathrm{~h}$ under the optimal conditions (Figure S1), but the growth of strain ZM05 and its degradation activity were significantly inhibited under Cd(II) stress (Figure 1). Through many coculture experiments, it was found that when ZM05 was cocultured with the nondegrading bacterium Acinetobacter tandoii ZM06, the residual DPrP and Cd(II) were significantly decreased (Figure 1).
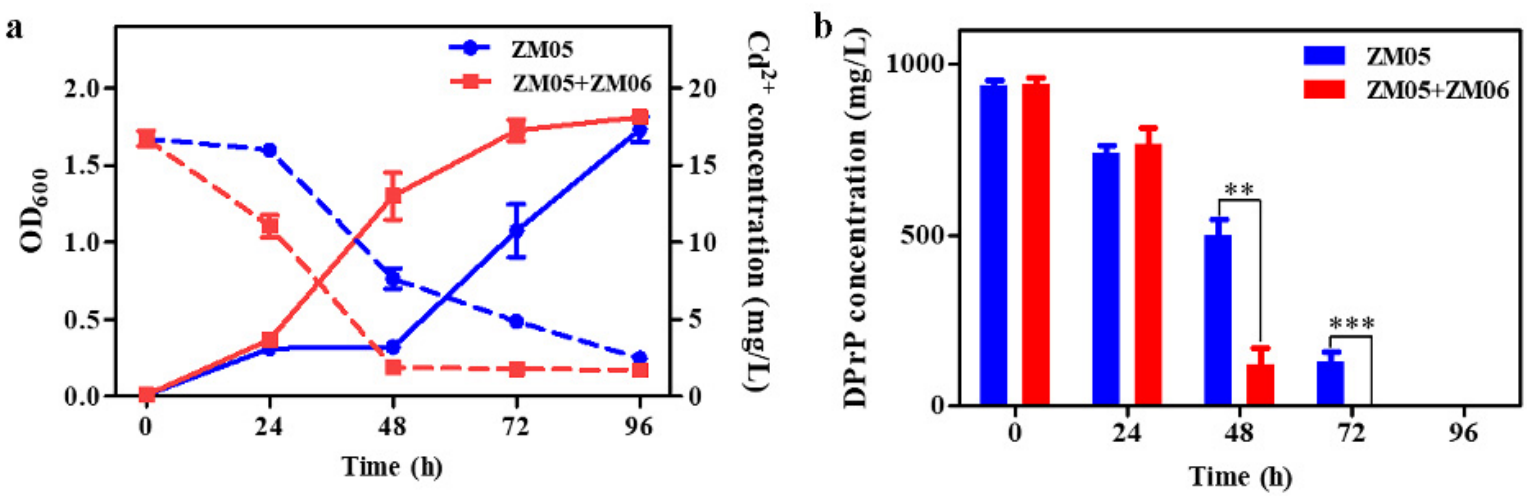

Figure 1. Growth and Cd(II) concentration (a) and DPrP degradation (b) in monoculture and coculture under Cd(II) contamination. The blue line (column) represents the monoculture of strain ZM05; the red line (column) represents the coculture of strains ZM05 and ZM06. The solid line represents the $\mathrm{OD}_{600}$, and the dotted line represents the residual concentration of $\mathrm{Cd}(\mathrm{II})$ in the supernatant. All data are presented as the mean $\pm \mathrm{SE}$. ${ }^{* *} p<0.001,{ }^{* *} p<0.01$.

\subsection{Strain ZM06 Relieved Cd (II) Stress in Coculture}

The degradation rate of DPrP increased significantly, and the Cd(II) concentration in the supernatant decreased noticeably when strain ZM05 was cocultured with strain ZM06 under Cd(II) stress (Figure 1a). To explore the mechanism of Cd(II) removal, SEM and TEM analyses were carried out. Primarily, SEM analysis was performed to compare the cell surface morphology before and after adsorption to determine whether ZM06 could alleviate the cytotoxicity caused by Cd(II) stress. As shown in Figure 2a,d, the surfaces of strains ZM05 and ZM06 were smooth and clear without adhesion before Cd(II) stress, while the morphologies of ZM05 and ZM06 changed significantly under Cd(II) stress, and many flaky substances, which were speculated to be the "microprecipitation" of inorganic salts, were adsorbed on the cell surface (Figure 2b,e).

To identify whether ZM05 and ZM06 reduce the free Cd(II) in the culture medium by absorbing $\mathrm{Cd}(\mathrm{II})$ into cells through active transport, TEM analysis and EDS analysis were used. There were obvious vacuoles in both ZM05 and ZM06 cells (Figure 2c,f), which indicated that the cells had stress responses to Cd(II) stress. However, EDS of the cytoplasm of ZM05 and ZM06 cells showed that neither ZM05 nor ZM06 accumulate Cd(II) or form any cadmium-containing phosphate granules intracellularly (Figure S2). 

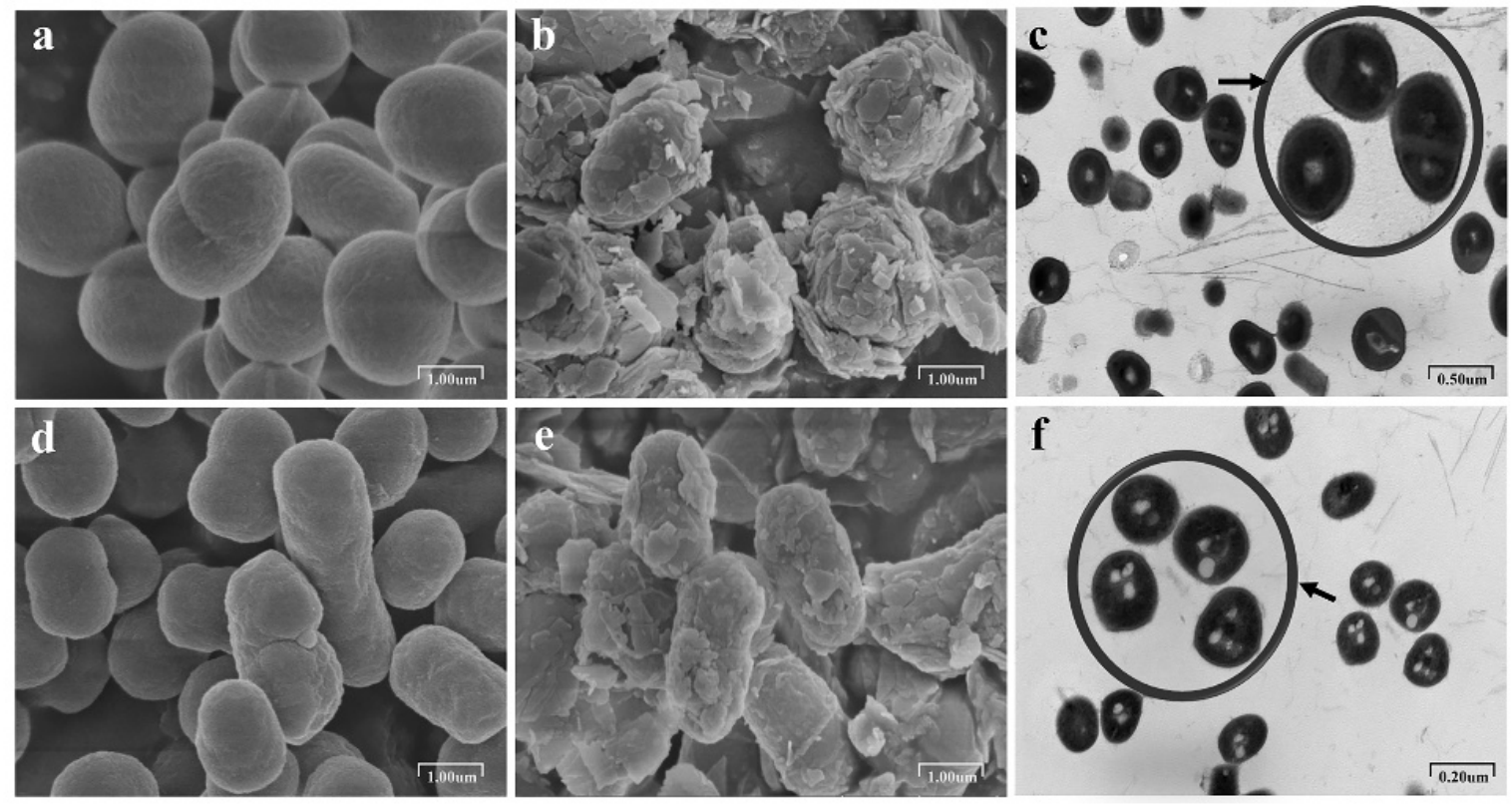

Figure 2. Cell surface morphologies of strains ZM05 (a) and ZM06 (d) without Cd(II) stress; cell surface morphologies of strains ZM05 (b) and ZM06 (e) with Cd(II) stress; TEM photographs of strains ZM05 (c) and ZM06 (f) after adsorption of Cd(II).

\subsection{Strain ZM06 Utilized the Metabolites of DPrP}

To detect the growth of strain ZM06 in the coculture system, qPCR was performed with specific primers. The nondegrading bacterium ZM06 was present in high proportions during the logarithmic growth period (Figure S3). To explore the survival mechanism of strain ZM06 in the coculture system and the interaction mechanism between strains ZM05 and ZM06 under Cd(II) stress, monoculture and coculture experiments supplied with DPrP or its metabolites (DEP, DMP, MEP, MMP, PA, or PCA) were performed. The detection of growth ability and substrates metabolic ability in mono- and coculture showed that ZM06 could utilize the downstream intermediates of DPrP produced by ZM05 as carbon source, including MEP, MMP, PA, and PCA (Figure 3). In particular, the degradation efficiency of DEP and DMP in the coculture system was significantly higher than those in the monoculture of strain ZM05.
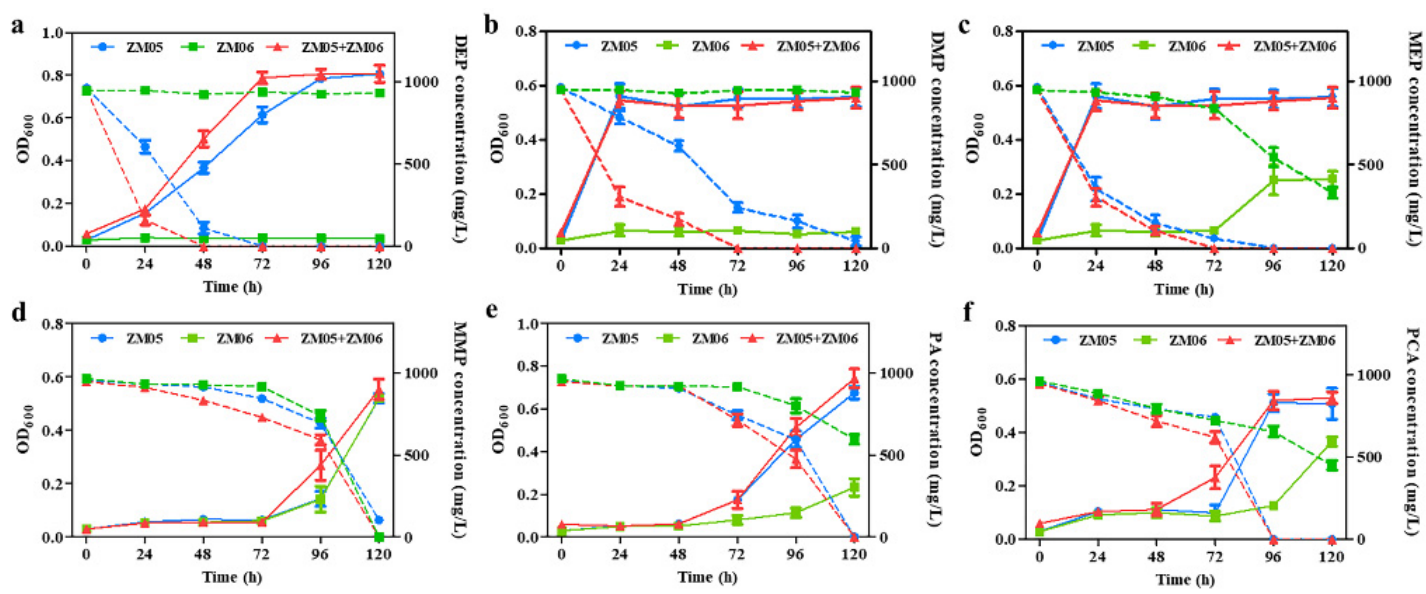

Figure 3. Growth and degradation characteristics of ZM05 (blue), ZM06 (green), and coculture (red) of ZM05 and ZM06 when supplemented with DEP (a), DMP (b), MEP (c), MMP (d), PA (e) or PCA (f) as the sole carbon source under Cd(II) contamination. The solid line represents the $\mathrm{OD}_{600}$, and the dotted line represents the residual concentration of the carbon source in the medium. All data are shown as the mean $\pm \mathrm{SE}$. 


\subsection{Transcriptional Response of Strain ZM05 to Cd(II) Stress in Monoculture}

To analyze the impacts of Cd(II) on the gene expression of strain ZM05 during DPrP degradation, transcriptional differences between strain ZM05 with and without Cd(II) stress in monoculture systems were determined. The results of the comparative transcriptomic analysis revealed 579 significantly upregulated genes and 439 significantly downregulated genes in strain ZM05 under Cd(II) stress (Figure 4a). The DEGs of strain ZM05 without $\mathrm{Cd}(\mathrm{II})$ stress vs. ZM05 with Cd(II) stress were significantly identified in "metabolism", "genetic information processing" and "environmental information processing" (Figure $4 \mathrm{~b}$ ). Upregulated DEGs related to 'metabolism of cofactors and vitamins', 'energy metabolism', 'amino acid metabolism', 'translation' and 'folding, sorting and degradation' outnumbered downregulated DEGs. A converse trend was obtained in 'signal transduction' and 'membrane transport', in which downregulated DEGs outnumbered upregulated DEGs. As shown in Figure S4a, genes involved in quorum sensing, ABC transporters, two-component systems, pyruvate metabolism, fatty acid degradation, and benzoate degradation were downregulated, while genes involved in the ribosome, oxidative phosphorylation, purine metabolism, and the citrate cycle were upregulated when strain ZM05 was grown under $\mathrm{Cd}(\mathrm{II})$ stress. These results indicated that Cd(II) stress inhibited the normal activity of strain ZM05, which was followed by a stress response.

a

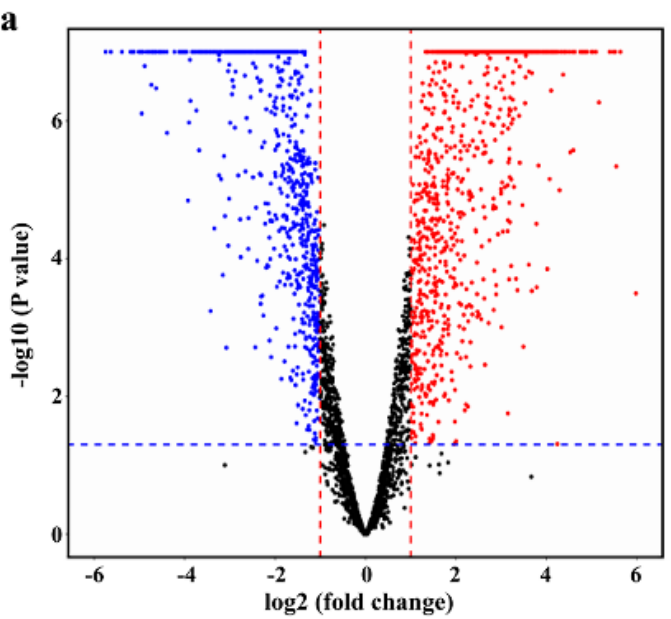

b

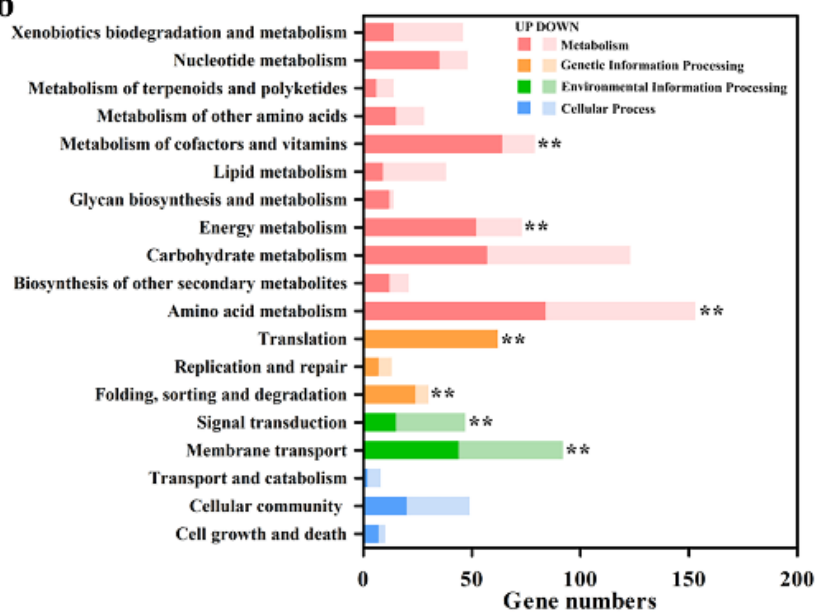

Figure 4. Volcano plot (a) and KEGG enrichment analysis (b) of DEGs from strain ZM05 with or without Cd(II) stress. ** $p<0.01$.

\subsection{Gene Expression of Strain ZM05 in Coculture and Monoculture}

In light of the DPrP degradation behavior (Figure S1), strain ZM06 synergistic promoted DPrP degradation by strain ZM05 when cultured under Cd(II) stress but had no such effect when grown without $C$ d(II) stress. Hence, we assumed that under Cd(II) stress, strain ZM06 could affect the gene expression of strain ZM05 in coculture systems. The volcano map reveals that strain ZM06 influenced the gene expression of strain ZM05 in the coculture system under Cd(II) stress, which represented 343 upregulated genes and 212 downregulated genes (Figure 5a). The significant DEGs of strain ZM05 in the monoculture system vs. ZM05 in the coculture system were mainly identified in "metabolism" and "environmental information processing" (Figure 5b). The upregulated DEGs related to 'signal transduction', 'amino acid metabolism' and 'membrane transport' outnumbered the downregulated DEGs significantly, while the upregulated DEGs related to 'nucleotide metabolism' and 'metabolism of cofactors and vitamins' were significantly fewer than the downregulated DEGs. As shown in Figure S4b, the depleted KEGG pathways from strain ZM05 included ribosome and valine, leucine, and isoleucine biosynthesis; other KEGG pathways, including quorum sensing, $\mathrm{ABC}$ transporters, two-component system, glycolysis, pyruvate metabolism, and benzoate degradation, were upregulated. 

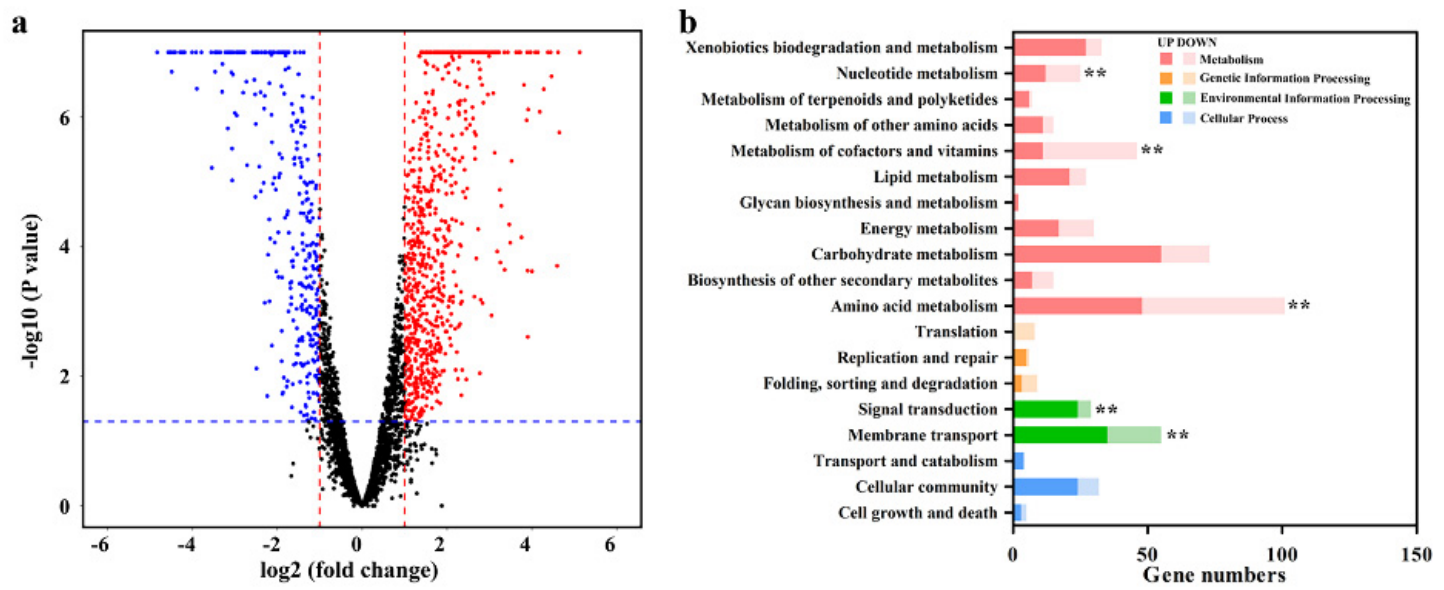

Figure 5. Volcano plot (a) and KEGG enrichment analysis (b) of DEGs from strain ZM05 in the monoculture system or coculture system under Cd(II) stress. ${ }^{* *} p<0.01$.

\section{Discussion}

The coexistence of cadmium with DPrP in the environment is a particular challenge for bioremediation because cadmium is toxic and cannot be degraded by biological processes [37]. However, the DPrP-degrading bacterium ZM05 shows weak resistance to Cd(II) stress, with a low rate of growth and DPrP degradation. To address environmental pressure, the synergistic relationships among microbes can be advantageous [38,39]. According to the analysis of DPrP degradation, cooperative interaction between strains ZM05 and ZM06 forms when straining ZM05 experiences Cd(II) stress.

\subsection{Cd (II) Strongly Stressed Strain ZM05}

Cadmium, one of the most toxic heavy metals, can disrupt cell proliferation and differentiation, cell cycle progression, apoptosis, and other cellular activities by proteotoxicity and DNA damage induced by oxidative stress [40,41]. Furthermore, microorganisms can alter their structure, physiology, and metabolic ability in detrimental environments [42]. In this study, SEM results revealed that the morphology of strain ZM05 was significantly changed, and bacteria formed insoluble cadmium salts under Cd(II) stress. Changes in the morphology of microorganisms after heavy metal biosorption generate an adaptive mechanism for surviving the stress forced by heavy metals [43]. As reported previously, $\mathrm{Cd}(\mathrm{II})$ stress clearly caused membrane indentations and decreased the surface area/volume ratio of Acidiphilium symbioticum H8, resulting in more elongated cells [44].

In response to $\mathrm{Cd}(\mathrm{II})$ stress, strain $\mathrm{ZM} 05$ upregulates genes involved in a stress response such as cold shock protein $(\operatorname{csp} A)$, riboflavin synthesis genes (rib), and thioredoxin reductase $(\operatorname{tr} x B, T R R)$ (Table $S 3)$. Cold shock proteins play important roles in transcription, mRNA stability, and translation [45], and riboflavin, as an important coenzyme of oxidoreductases, prevents oxidative stress [46]. Thioredoxin also serves as a stress-response factor in some bacteria [47]. The upregulation of genes involved in the stress response suggests that $\mathrm{Cd}$ (II) causes strong environmental stress on strain ZM05. Interestingly, the expression of the ribosome was significantly upregulated, suggesting that the ribosome probably plays an important role in the repair of cadmium-mediated cellular damage [48].

\subsection{Strain ZM06 Accelerated the Degradation of DPrP}

Many degrading bacteria are closely related to other microbes, and they constitute composite microbial degradation systems with improved capability [49], especially in an unfavorable environment, microbes prefer to form consortia to resist stress [15]. In this study, both strains ZM05 and ZM06 adsorbed cadmium on the surface and did not transport Cd(II) into cells. The addition of strain ZM06 greatly reduced the concentration 
of free cadmium in the culture system. The results illustrated that the nondegrading bacterium ZM06 relieved the stress of Cd(II) on the degrading bacterium ZM05.

Simultaneously, microbes can cooperate with the bacteria that metabolize the downstream metabolites to form bacterial consortia to accelerate the degradation of organic pollutants [50,51]. Under Cd(II) stress, the accelerated degradation of DPrP was presumable attributed to faster depletion of downstream intermediates by strain ZM06 in the coculture system (Figure 3). Strain ZM05 downregulated the genes responsible for the upstream metabolism of DPrP degradation but upregulated the genes responsible for the downstream metabolism in the monoculture system under Cd(II) stress, which indicated that stress impeded the committed step during degradation (Table S4). When cocultured with strain ZM06, the variations in the transcriptional levels of the genes involved in DPrP degradation occurred in the opposite directions of the variations in the monoculture. The utilization of DPrP downstream metabolites by strain ZM06 not only relieved the inhibition of metabolites but also accelerated the key degradation steps of strain ZM05. Reducing the accumulation of intermediates and thus accelerating the consumption of substrates that produce growth-inhibiting intermediates, is important to optimize the desired biotransformation [52].

\subsection{Strain ZM06 Contributed Amino Acids and Fatty Acids to Strain ZM05}

In cooperative relationships of microbes, the exchange of substances occurs frequently [53]. Under Cd(II) stress, monoculture of strain ZM05 upregulated valine, leucine, and isoleucine biosynthesis, while coculture with ZM06 downregulated valine, leucine, and isoleucine biosynthesis (Figure S4). At the same time, strain ZM05 upregulated the genes involved in translation in monoculture but downregulated the genes involved in translation when cocultured with strain ZM06 (Figures $4 \mathrm{~b}$ and $5 \mathrm{~b}$ ). Moreover, the concentration of leucine in coculture was significantly higher than that in monoculture (Figure S6b). The results indicated that strain ZM06 probably offers amino acids and proteins to strain ZM05 under $\mathrm{Cd}(\mathrm{II})$ stress.

Similarly, $\mathrm{Cd}(\mathrm{II})$ stress caused the downregulation of fatty acid degradation required for energy production in strain ZM05 in the monoculture system. Strain ZM05 upregulated fatty acid degradation in the coculture system (Figure S4). And the detected palmitic acid was more abundant in the coculture system (Figure S5b). We suggest that strain ZM06 may contribute fatty acids to support the response of strain ZM05 to Cd(II) stress. Bacterial communities can make efficient use of limited resources through metabolites exchange, providing survival advantages under challenging conditions [54]. Strain ZM06 effectively alleviated Cd(II) stress on ZM05, and much substance and signal communication occurred between strains ZM05 and ZM06.

\subsection{Mechanism of Cooperation between Strain ZM05 and Strain ZM06}

According to the above results, we construct a model of the interaction between the DPrP-degrading bacterium ZM05 and the nondegrading bacterium ZM06, as shown in Figure 6. In a coculture system, DPrP was degraded by strain ZM05, and readily available intermediates were utilized not only by strain ZM05 but also by strain ZM06 as a carbon source. The stress of $\mathrm{Cd}$ (II) leads to significant changes in the expression of genes involved in the crucial step of DPrP degradation, signal transduction, and energy metabolism. The symbiotic bacterium ZM06, surviving on the metabolites of DPrP, supplies amino acids and fatty acids to strain ZM05 to coping with stress. At the same time, the coculture strengthened the signaling and substrate communication between the two bacteria, and the coculture system is stable and efficiently degrades DPrP. 

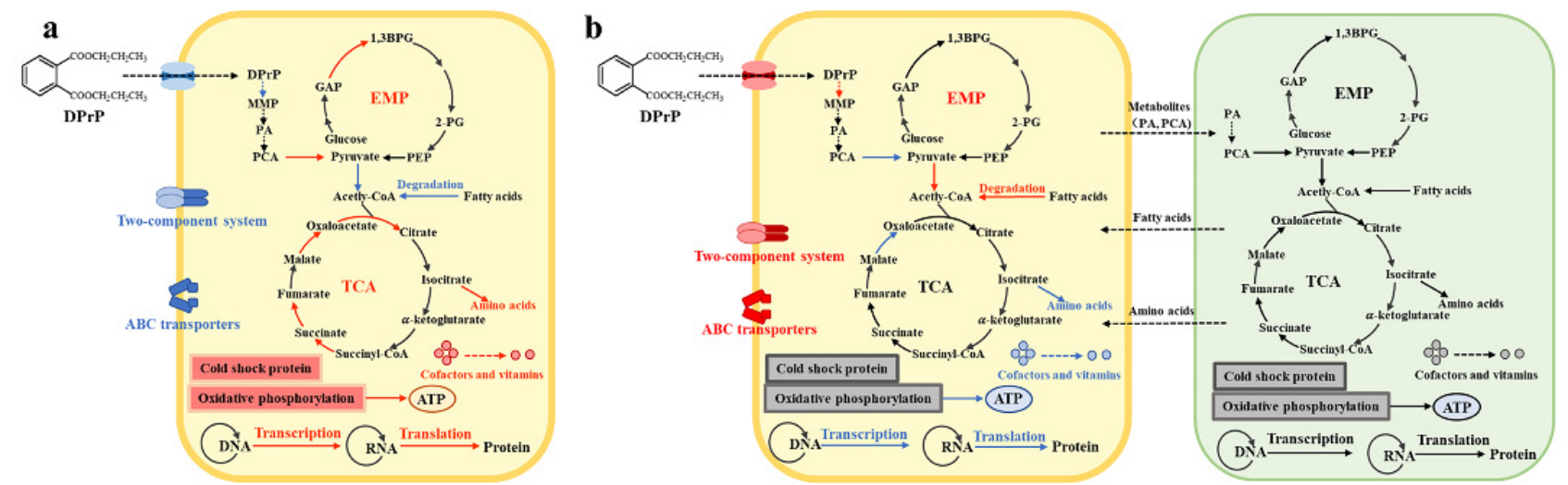

Figure 6. Schematic mechanism of strain ZM05 under Cd(II) stress (a) and the interactions between strain ZM05 and strain ZM06 (b)during DPrP biodegradation. Yellow oblong represents strain ZM05; green oblong represents strain ZM06. The red text represents upregulated metabolism; blue text represents downregulated metabolism.

\section{Conclusions}

In summary, this study proves that a consortium of the DPrP-degrading bacterium ZM05 and the nondegrading bacterium ZM06 has an improved performance in degrading DPrP under Cd(II) stress. Strain ZM06 could not degrade DPrP, but it offers fatty acids and amino acids to strain $\mathrm{ZM} 05$ in response in the coculture system, which might relieve the pressure on strain ZM05. Our results clarify the interactions within the synergistic community during DPrP degradation under Cd(II) stress and hint at environmental pressure as a major driver of species co-occurrence. Moreover, this study provides new insights and theoretical basis for the application of microbial consortium in the remediation of pollutants in an unfavorable environment.

Supplementary Materials: The following are available online at https: / www.mdpi.com/article/ 10.3390/microorganisms9071417/s1, Table S1: Primers used for quantitative PCR, Table S2: The information for the transcriptomic sample; Table S3: Gene involved in the stress response of strain ZM05 annotated by KEGG database; Table S4: Degradation gene of strain ZM05 annotated by KEGG database; Figure S1: Growth curve and DPrP degradation behavior in monoculture and coculture under optimum conditions; Figure S2: EDS analysis of strain ZM05 and ZM06 under Cd (II) stress; Figure S3: Relative abundances of strain ZM05 and strain ZM06 in coculture system under Cd (II) stress; Figure S4: KEGG analyses of DEGs from strain ZM05 with or without Cd (II) stress and strain ZM05 in the mono-culture system or coculture system under Cd (II) stress; Figure S5. Amino acids and fatty acids in monoculture and coculture systems under Cd (II) stress.

Author Contributions: Z.L. was the academic supervisor, proposed the original conceptualization, and critically guided the completion of the research; methodology and validation, X.W. and S.S.; data curation, X.W., S.S. and L.W.; writing-original draft preparation, X.W.; writing-review and editing, H.W. (Haixia Wang) and H.W. (Hao Wu). All authors have read and agreed to the published version of the manuscript.

Funding: This work was supported by the National Natural Science Foundation of China (41721001 and 41630637).

Conflicts of Interest: The authors declare no conflict of interest. The funders had no role in the design of the study; in the collection, analyses, or interpretation of data; in the writing of the manuscript; or in the decision to publish the results. 


\section{References}

1. Liang, D.W.; Zhang, T.; Fang, H.H.P.; He, J. Phthalates biodegradation in the environment. Appl. Microbiol. Biotechnol. 2008, 80, 183-198. [CrossRef] [PubMed]

2. Kim, Y.H.; Min, J.; Bae, K.D.; Gu, M.B.; Lee, J. Biodegradation of dipropyl phthalate and toxicity of its degradation products: A comparison of Fusarium oxysporum f. sp. pisi cutinase and Candida cylindracea esterase. Arch. Microbiol. 2005, 184, 25-31. [CrossRef] [PubMed]

3. He, B.S.; Li, J.W. Synthesis of gold nanocubes/PEI-wrinkled CoSe(2)nanomaterials and its application in electrochemical immunosensors for detection of dipropyl phthalate. Rare Met. 2020, 40, 1099-1109. [CrossRef]

4. Zhang, C.; Tao, Y.; Li, S.; Tian, J.; Ke, T.; Wei, S.; Wang, P.; Chen, L. Simultaneous degradation of trichlorfon and removal of Cd(II) by Aspergillus sydowii strain PA F-2. Environ. Sci. Pollut. Res. 2019, 26, 26844-26854. [CrossRef]

5. Crain, C.M.; Kroeker, K.; Halpern, B.S. Interactive and cumulative effects of multiple human stressors in marine systems. Ecol. Lett. 2008, 11, 1304-1315. [CrossRef] [PubMed]

6. Peng, H.; Gao, P.; Chu, G.; Pan, B.; Peng, J.; Xing, B. Enhanced adsorption of Cu(II) and Cd(II) by phosphoric acid-modified biochars. Environ. Pollut. 2017, 229, 846-853. [CrossRef] [PubMed]

7. Mirlean, N.; Roisenberg, A. The effect of emissions of fertilizer production on the environment contamination by cadmium and arsenic in southern Brazil. Environ. Pollut. 2006, 143, 335-340. [CrossRef]

8. Rao, Z.X.; Huang, D.Y.; Wu, J.S.; Zhu, Q.H.; Zhu, H.H.; Xu, C.; Xiong, J.; Wang, H.; Duan, M.M. Distribution and availability of cadmium in profile and aggregates of a paddy soil with 30-year fertilization and its impact on Cd accumulation in rice plant. Environ. Pollut. 2018, 239, 198-204. [CrossRef]

9. Zhang, W.H.; Wu, Y.X.; Simonnot, M.O. Soil Contamination due to E-Waste Disposal and Recycling Activities: A Review with Special Focus on China. Pedosphere 2012, 22, 434-455. [CrossRef]

10. Adeniyi, A.; Dayomi, M.; Siebe, P.; Okedeyi, O. An assessment of the levels of phthalate esters and metals in the Muledane open dump, Thohoyandou, Limpopo Province, South Africa. Chem. Cent. J. 2008, 2. [CrossRef]

11. Stoppa, F.; Schiazza, M.; Pellegrini, J.; Ambrosio, F.A.; Rosatelli, G.; D'Orsogna, M.R. Phthalates, heavy metals and PAHs in an overpopulated coastal region: Inferences from Abruzzo, central Italy. Mar. Pollut. Bull. 2017, 125, 501-512. [CrossRef]

12. Luo, L.; Meng, H.; Gu, J.-D. Microbial extracellular enzymes in biogeochemical cycling of ecosystems. J. Environ. Manag. 2017, 197, 539-549. [CrossRef]

13. Li, N.; Liu, R.; Chen, J.; Wang, J.; Hou, L.; Zhou, Y. Enhanced phytoremediation of PAHs and cadmium contaminated soils by a Mycobacterium. Sci. Total Environ. 2021, 754. [CrossRef] [PubMed]

14. Geiger, R.A.; Junghare, M.; Mergelsberg, M.; Ebenau-Jehle, C.; Jesenofsky, V.J.; Jehmlich, N.; von Bergen, M.; Schink, B.; Boll, M. Enzymes involved in phthalate degradation in sulphate-reducing bacteria. Environ. Microbiol. 2019, 21, 3601-3612. [CrossRef]

15. Liu, Z.B.; He, Z.X.; Huang, H.; Ran, X.B.; Oluwafunmilayo, A.O.; Lu, Z.M. pH Stress-Induced Cooperation between Rhodococcus ruber YYL and Bacillus cereus MLY1 in Biodegradation of Tetrahydrofuran. Front. Microbiol. 2017, 8, 2297. [CrossRef] [PubMed]

16. Mikeskova, H.; Novotny, C.; Svobodova, K. Interspecific interactions in mixed microbial cultures in a biodegradation perspective. Appl. Microbiol. Biotechnol. 2012, 95, 861-870. [CrossRef]

17. Saratale, R.G.; Saratale, G.D.; Kalyani, D.C.; Chang, J.S.; Govindwar, S.P. Enhanced decolorization and biodegradation of textile azo dye Scarlet R by using developed microbial consortium-GR. Bioresour. Technol. 2009, 100, 2493-2500. [CrossRef]

18. Wu, X.; Liang, R.; Dai, Q.; Jin, D.; Wang, Y.; Chao, W. Complete degradation of di-n-octyl phthalate by biochemical cooperation between Gordonia sp. strain JDC-2 and Arthrobacter sp. strain JDC-32 isolated from activated sludge. J. Hazard. Mater. 2010, 176, 262-268. [CrossRef] [PubMed]

19. Roane, T.M.; Josephson, K.L.; Pepper, I.L. Dual-bioaugmentation strategy to enhance remediation of cocontaminated soil. Appl. Environ. Microbiol. 2001, 67, 3208-3215. [CrossRef] [PubMed]

20. Wang, X.J.; Wu, H.; Wang, X.Y.; Wang, H.X.; Zhao, K.K.; Ma, B.; Lu, Z.M. Network-directed isolation of the cooperator Pseudomonas aeruginosa ZM03 enhanced the dibutyl phthalate degradation capacity of Glutamicibacter nicotianae ZM05 under pH stress. J. Hazard. Mater. 2021, 410. [CrossRef]

21. Jain, C.; Rodriguez-R, L.M.; Phillippy, A.M.; Konstantinidis, K.T.; Aluru, S. High throughput ANI analysis of $90 \mathrm{~K}$ prokaryotic genomes reveals clear species boundaries. Nat. Commun. 2018, 9, 5114. [CrossRef]

22. Lee, I.; Kim, Y.O.; Park, S.C.; Chun, J. OrthoANI: An improved algorithm and software for calculating average nucleotide identity. Int. J. Syst. Evol. Microbiol. 2016, 66, 1100-1103. [CrossRef] [PubMed]

23. He, Z.X.; Niu, C.Z.; Lu, Z.M. Individual or synchronous biodegradation of di-n-butyl phthalate and phenol by Rhodococcus ruber strain DP-2. J. Hazard. Mater. 2014, 273, 104-109. [CrossRef] [PubMed]

24. Zhu, F.; Doyle, E.; Zhu, C.; Zhou, D.; Gu, C.; Gao, J. Metagenomic analysis exploring microbial assemblages and functional genes potentially involved in di (2-ethylhexyl) phthalate degradation in soil. Sci. Total Environ. 2020, 715. [CrossRef]

25. Matsumoto, M.; Kunisawa, A.; Hattori, T.; Kawana, S.; Kitada, Y.; Tamada, H.; Kawano, S.; Hayakawa, Y.; Iida, J.; Fukusaki, E. Free D-amino acids produced by commensal bacteria in the colonic lumen. Sci. Rep. 2018, 8. [CrossRef]

26. Zhang, S.M.; Wang, H.B.; Zhu, M.J. A sensitive GC/MS detection method for analyzing microbial metabolites short chain fatty acids in fecal and serum samples. Talanta 2019, 196, 249-254. [CrossRef]

27. Xue, C.; Qi, P.; Li, M.; Liu, Y. Characterization and sorptivity of the Plesiomonas shigelloides strain and its potential use to remove $\mathrm{Cd}^{2+}$ from wastewater. Water 2016, 8, 241. [CrossRef] 
28. Wang, R.; Wei, S.; Jia, P.; Liu, T.; Hou, D.; Xie, R.; Lin, Z.; Ge, J.; Qiao, Y.; Chang, X.; et al. Biochar significantly alters rhizobacterial communities and reduces $C d$ concentration in rice grains grown on Cd-contaminated soils. Sci. Total Environ. 2019, 676, 627-638. [CrossRef] [PubMed]

29. Ho, M.T.; Li, M.S.M.; McDowell, T.; MacDonald, J.; Yuan, Z.C. Characterization and genomic analysis of a diesel-degrading bacterium, Acinetobacter calcoaceticus CA16, isolated from Canadian soil. BMC Biotechnol. 2020, 20, 39. [CrossRef] [PubMed]

30. Whangsuk, W.; Sungkeeree, P.; Nakasiri, M.; Thiengmag, S.; Mongkolsuk, S.; Loprasert, S. Two endocrine disrupting dibutyl phthalate degrading esterases and their compensatory gene expression in Sphingobium sp. SM42. Int. Biodeterior. Biodegrad. 2015, 99, 45-54. [CrossRef]

31. Bolger, A.M.; Lohse, M.; Usadel, B. Trimmomatic: A flexible trimmer for Illumina sequence data. Bioinformatics 2014, 30, 2114-2120. [CrossRef]

32. Kim, D.; Langmead, B.; Salzberg, S.L. HISAT: A fast spliced aligner with low memory requirements. Nat. Methods 2015, 12, 357-360. [CrossRef] [PubMed]

33. Anders, S.; Pyl, P.T.; Huber, W. HTSeq-A Python framework to work with high-throughput sequencing data. Bioinformatics 2015, 31, 166-169. [CrossRef]

34. Pertea, M.; Kim, D.; Pertea, G.M.; Leek, J.T.; Salzberg, S.L. Transcript-level expression analysis of RNA-seq experiments with HISAT, StringTie and Ballgown. Nat. Protoc. 2016, 11, 1650-1667. [CrossRef] [PubMed]

35. Robinson, M.D.; McCarthy, D.J.; Smyth, G.K. edgeR: A Bioconductor package for differential expression analysis of digital gene expression data. Bioinformatics 2010, 26, 139-140. [CrossRef]

36. Yu, G.; Wang, L.-G.; Han, Y.; He, Q.-Y. clusterProfiler: An R package for comparing biological themes among gene clusters. OMICS J. Integr. Biol. 2012, 16, 284-287. [CrossRef] [PubMed]

37. Yang, M.; Zhang, H.; Ni, J.; Chen, W.; Yang, L.; Wei, R. Effect of cadmium on pyrene biodegradation in solution and soil using free and immobilized Escherichia sp. on biochar. Appl. Soil Ecol. 2020, 150. [CrossRef]

38. Ma, X.K.; Ding, N.; Peterson, E.C.; Daugulis, A.J. Heavy metals species affect fungal-bacterial synergism during the bioremediation of fluoranthene. Appl. Microbiol. Biotechnol. 2016, 100, 7741-7750. [CrossRef] [PubMed]

39. Ren, C.-G.; Bai, Y.-J.; Kong, C.-C.; Bian, B.; Xie, Z.-H. Synergistic interactions between salt-tolerant rhizobia and arbuscular mycorrhizal fungi on salinity tolerance of Sesbania cannabina plants. J. Plant Growth Regul. 2016, 35, 1098-1107. [CrossRef]

40. Aimola, P.; Carmignani, M.; Volpe, A.R.; Di Benedetto, A.; Claudio, L.; Waalkes, M.P.; van Bokhoven, A.; Tokar, E.J.; Claudio, P.P. Cadmium induces p53-dependent apoptosis in human prostate epithelial cells. PLoS ONE 2012, 7. [CrossRef]

41. Anju, R.; Anuj, K.; Ankita, L.; Manu, P. Cellular mechanisms of cadmium-induced toxicity: A review. Int. J. Environ. Health Res. 2014, 24, 378-399.

42. Cefali, E.; Patane, S.; Arena, A.; Saitta, G.; Guglielmino, S.; Cappello, S.; Nicolo, M.; Allegrini, M. Morphologic variations in bacteria under stress conditions: Near-field optical studies. Scanning 2002, 24, 274-283. [CrossRef] [PubMed]

43. George, B.; Kumar, J.I.N.; Kumar, R.N.; Sajish, P.R. Biosorption potentiality of living Aspergillus niger Tiegh in removing heavy metal from aqueous solution. Bioremediat. J. 2012, 16, 195-203. [CrossRef]

44. Chakravarty, R.; Banerjee, P.C. Morphological changes in an acidophilic bacterium induced by heavy metals. Extremophiles 2008, 12, 279-284. [CrossRef]

45. Holmqvist, E.; Vogel, J. RNA-binding proteins in bacteria. Nat. Rev. Microbiol. 2018, 16, 601-615. [CrossRef]

46. Chen, J.; Shen, J.; Solem, C.; Jensen, P.R. Oxidative stress at high temperatures in Lactococcus lactis due to an insufficient supply of riboflavin. Appl. Environ. Microbiol. 2013, 79, 6140-6147. [CrossRef]

47. Ritz, D.; Beckwith, J. Roles of thiol-redox pathways in bacteria. Annu. Rev. Microbiol. 2001, 55, 21-48. [CrossRef]

48. El-Rab, S.M.F.G.; Shoreit, A.A.F.; Fukumori, Y. Effects of cadmium stress on growth, morphology, and protein expression in Rhodobacter capsulatus B10. Biosci. Biotechnol. Biochem. 2006, 70, 2394-2402. [CrossRef]

49. Kadam, A.A.; Telke, A.A.; Jagtap, A.S.; Govindwar, S.P. Decolorization of adsorbed textile dyes by developed consortium of Pseudomonas sp. SUK1 and Aspergillus ochraceus NCIM-1146 under solid state fermentation. J. Hazard. Mater. 2011, 189, 486-494. [CrossRef]

50. Drzyzga, O.; Gottschal, J.C. Tetrachloroethene dehalorespiration and growth of Desulfitobactetium frappieri TCE1 in strict dependence on the activity of Desulfovibrio fructosivorans. Appl. Environ. Microbiol. 2002, 68, 642-649. [CrossRef]

51. Holmes, V.F.; He, J.; Lee, P.K.H.; Alvarez-Cohen, L. Discrimination of multiple Dehalococcoides strains in a trichloroethene enrichment by quantification of their reductive dehalogenase genes. Appl. Environ. Microbiol. 2006, 72, 5877-5883. [CrossRef]

52. Lilja, E.E.; Johnson, D.R. Segregating metabolic processes into different microbial cells accelerates the consumption of inhibitory substrates. ISME J. 2016, 10, 1568-1578. [CrossRef] [PubMed]

53. Nobu, M.K.; Narihiro, T.; Rinke, C.; Kamagata, Y.; Tringe, S.G.; Woyke, T.; Liu, W.T. Microbial dark matter ecogenomics reveals complex synergistic networks in a methanogenic bioreactor. ISME J. 2015, 9, 1710-1722. [CrossRef] [PubMed]

54. Zelezniak, A.; Andrejev, S.; Ponomarova, O.; Mende, D.R.; Bork, P.; Patil, K.R. Metabolic dependencies drive species co-occurrence in diverse microbial communities. Proc. Natl. Acad. Sci. USA 2015, 112, 6449-6454. [CrossRef] [PubMed] 